Please do not remove this page

RMIT

UNIVERSITY

\title{
Examining empathy and perspective taking among high-risk and low-risk persistently antisocial and nonantisocial young adults
}

Zafirakis, Effie

https://researchrepository.rmit.edu.au/esploro/outputs/9921857909201341/filesAndLinks?institution=61RMIT_INST\&index=null

Zafirakis, E. (2009). Examining empathy and perspective taking among high-risk and low-risk persistently antisocial and nonantisocial young adults. The International Journal of Interdisciplinary Social Sciences, 4(7), 193-204.

https://researchrepository.rmit.edu.au/discovery/fulldisplay/alma9921857909201341/61RMIT_INST:Resea rchRepository

Document Version: Published Version

Repository homepage: https://researchrepository.rmit.edu.au

(c) 2009 Common Ground, Effie Zafirakis, All Rights Reserved

Downloaded On 2023/04/26 18:34:23 +1000 

antisocial and nonantisocial young adults', The International Journal of Interdisciplinary Social Sciences, vol. 4, no. 7, pp. 193-204.

\title{
Examining Empathy and Perspective Taking Among High-Risk and Low-Risk Persistently Antisocial and Non Antisocial Young Adults
}

\author{
Effie Zafirakis, RMIT University, Victoria, Australia
}

\begin{abstract}
The present study investigated empathy and perspective taking of three groups: high-risk persistently antisocial, low-risk persistently antisocial and non-antisocial young adults. Antisocial behaviour refers to acts such as thefts, drug dealing, bullying and fighting. In particular, gender and group-related differences of young adults with differing histories of antisocial behaviour (namely, high-risk persistently antisocial, low-risk persistently antisocial and non-antisocial groups) were examined. One hundred and thirty-eight participants, aged 22 to 23 years of age, were interviewed by phone. Participants were drawn from the Australian Temperament Project (ATP) which is a prospective longitudinal study that has tracked pathways of antisocial behaviour and psychosocial adjustment from infancy to young adulthood. An examination of group and gender differences found that highrisk persistently antisocial youth endorsed lower levels of affective empathy, as measured by the empathic concern subscale on the Interpersonal Reactivity Index (IRI), compared to their non-antisocial counterparts. Female participants also reported higher levels of affective empathy than male participants. No gender or group differences were found on the cognitive component of the IRI, as measured by the perspective taking subscale. In particular, this study suggests that both gender and the level of risk for persistently antisocial behaviour were significantly related to differences in empathy in young adulthood. Discussion is focused on the theoretical and practical implications of these findings.
\end{abstract}

Keywords: Persistent Antisocial Behaviour, Empathy and Perspective -Taking, High-risk and Lowrisk Persistently Antisocial Young Adults

\section{Introduction}

$\mathrm{I}$

T HAS WIDELY been acknowledged that youth aggression and persistent antisocial behaviour is a major social problem. Indeed, it appears that rates of interpersonal violence as displayed by youth in Australian society remain alarmingly high (Australian Institute of Criminology, 2006; Smart et al., 2005). Yet, despite the high prevalence of youth aggression and persistent antisocial behaviour into early adulthood, effective treatment for youth aggression is difficult, at least in terms of its long-term efficacy (Connor, 2002). There are certain limitations in this area of research that warrant further attention. First, there is a lack of prospective longitudinal studies that have explored the continuities of antisocial behaviour in young adulthood. Although arguably some effort has been made in recent years to describe the trajectories of growth and development of persistent antisocial behaviour across the childhood and adolescent years, very little research has examined the link between types of childhood and adolescent persistent antisocial behaviour and psychosocial outcomes in young adulthood. Second, in the research literature to date there has been a preponderance of studies focusing on social-cognitive deficits and interpersonal functioning of male youth

The International Journal of Interdisciplinary Social Sciences Volume 4, 2009, http://www.SocialSciences-Journal.com, ISSN 1833-1882 (C) Common Ground, Effie Zafirakis, All Rights Reserved, Permissions: cg-support@commongroundpublishing.com 
with comparatively little exploration of these psychosocial constructs in female youth (Bor, McGee, Hayatbakhsh \& Najman, 2007).

The present study examined dispositional empathy which it has been found to impact on interpersonal functioning and psychosocial adjustment in early adulthood and to be predictive of persistent antisocial behaviour in children and adolescence (Pettit \& Dodge, 2003).

\section{Transitions to Young Adulthood-Persistence of Antisocial Behaviour}

\section{Approaches to Explaining the Persistence of Antisocial Behaviour}

Reviews in relation to the persistence of antisocial behaviour have consistently shown notable continuities between childhood, adolescent and adult manifestations of antisocial behaviour (Loeber \& Coie, 2001; Maughan \& Rutter, 2001). One approach utilised in understanding the development and persistence of antisocial behaviour has focused on distinguishing subtypes of antisocial individuals from the perspective of differential developmental pathways of antisocial behaviour (Bor et al., 2007). Notably, Moffit (1993) has proposed an influential developmental model to explain differing patterns of antisocial behaviour based on age of onset. According to this model, for 'life-course persistent' antisocial individuals, antisocial behaviour manifests in early childhood and is characterised by stability and continuity of antisocial behaviour over an individual's life course. This pathway has been hypothesised to be "inflexible and refractory to changing circumstances" (Moffit, 1993, p. 686). In contrast, the 'adolescent-limited' sub-group consists of individuals who first exhibit antisocial behaviour in early adolescence. This pathway is proposed to be transient or of relatively limited duration and likely to show little continuity with antisocial behaviour in adulthood. More recently, however, research studies on adolescent antisocial behaviour show a greater complexity and diversity of pathways to antisocial behaviour than originally postulated by Moffit (1993). A number of studies have highlighted notable continuities between both childhood-onset and adolescent-onset antisocial behaviour in adulthood, a finding confirmed using both high-risk and normative samples (Smart et al., 2005; Moffit, Caspi, Harrington \& Milne, 2002; Farrington, 1995). For instance, Bor et al. (2007), using the Mater University Study of Pregnancy, a longitudinal prospective study that has followed an Australian birth cohort to age 21, tested the relationship between Moffit's (1993) typology of antisocial behaviour and young adult functioning. This study found that while the childhood-onset group demonstrated an increased risk for a range of self-reported adverse adult outcomes, the adolescent-onset group also experienced problems in adult functioning.

Another approach to explaining the persistence of antisocial behaviour distinguishes subtypes of antisocial individuals based on the concept of cumulative risk. Loeber, Green and Lahey (2003) define 'risk factors' as events or conditions associated with an increased likelihood of antisocial behaviour. Interestingly, it is the accumulation of risk factors as opposed to individual predictors that may encourage the persistence of aggressive and antisocial behaviours over time. Therefore, cumulative risk approaches that focus on multiple risk factors have higher predictive utility compared to research that simply examines specific patterns of individual risk factors over time (Cesaroni \& Peterson-Badali, 2005; Brennan et al., 2003). In particular, Smart et al. (2005) used a cumulative risk approach as well as considering the actual level of involvement for persistent antisocial behaviour to define groups of low-risk and high-risk persistently antisocial youth. The study found that the majority of individuals 
identified as persistently antisocial (both low-risk and high-risk) continued to engage in high levels of antisocial behaviour in early adulthood as measured at 19-20 years of age. Interestingly, in the case of the low-risk group the continuation of antisocial behaviour into young adulthood was unexpected given the lack of childhood indices for antisocial behaviour. An important caveat nonetheless is the consideration that the continuity of antisocial behaviour is not necessarily absolute or rigid. Rather it is a cumulative dynamic process whereby individual risk levels of antisocial behaviour may change depending on the interplay between an individual's characteristics, the environment and his or her exposure to risk factors (Loeber \& Coie, 2001).

Notably, prospective longitudinal studies using a cumulative risk approach are only now beginning to explore continuities of antisocial behaviour in young adulthood. Yet understanding the development of persistent antisocial behaviour arguably requires the use of longitudinal studies that follow at-risk children over time by mapping developmental trajectories to help predict the continuity of antisocial behaviour versus its attenuation. In seeking to address this neglected area of research, the current study (as a sub-study of the Australian Temperament Project) adopts the approach most recently used by Smart et al. (2005) to examine specific psychosocial outcomes of individuals identified as high-risk, low-risk persistently antisocial and non-antisocial individuals in young adulthood.

\section{Link between Persistent Antisocial Behaviour and Psychosocial Adjustment in Young Adulthood}

Young adulthood has increasingly been recognised as a key transition or 'turning' point in an individual's life course which is associated with a unique set of relational challenges (Caspi, 2000). It has been proposed that young adulthood can represent a transition period which brings lasting changes in an individual's interpersonal relationships and psychosocial functioning (Maughan \& Rutter, 2001).

Researchers suggest that a characteristic feature associated with persistent antisocial behaviour is the pervasiveness of psychosocial adversities encountered in young adulthood (Maughan \& Rutter, 2001). Accordingly, from a cumulative risk perspective, it seems that persistent antisocial behaviour not only predicts the continuity of antisocial behaviour but also a wide range of problems in adult psychosocial adjustment, highlighting the continuing impact of persistent antisocial behaviour in young adulthood (Bor et al., 2007; Smart et al., 2005). In particular, research findings suggest that adolescents with persistent antisocial behaviour show chronic problems in their interpersonal relationships and social functioning (Maughan \& Rutter, 2001; Zoccolillo, Pickles, Quinton \& Rutter, 1992). Social skills deficits associated with difficulties in interpersonal functioning and empathy deficits may therefore play an influential role in the persistence of antisocial behaviour. Major life experiences associated with the transition to young adulthood and the unique challenges this period may present, in turn, may accentuate rather than ameliorate an individual's existing social skill deficits.

\section{Empathy and Persistent Antisocial Behaviour}

Empathy is a multidimensional construct characterised by sensitivity toward the feelings of others, consisting of both affective and cognitive components (Davis, 1983; Hoffman, 2000). 
Eisenberg and Miller (1987) define empathy as "an affective state that stems from the apprehension of another's emotional state or condition and that is congruent with it" (p. 91). Implicit in this definition of empathy is the co-existence of two components, namely the affective component which is characterised by the ability to 'vicariously' experience another's feelings or demonstrate a concordant emotional response, and a cognitive component which entails the ability to understand another's perspective (Loudin, Loukas \& Robinson, 2003).

\section{Empathy and Aggressive Behaviour}

An extensive body of research has consistently found that empathy is inversely related to aggression (Hoffman, 2000). This relationship is stronger for questionnaire or self-report measures of empathy than for other experimentally induced methods. Researchers have also reported that low levels of empathy are associated with aggressive behaviour and externalising problems in adolescence (Carlo, Raffaelli, Laible \& Meyer, 1999). Not surprisingly, empathy has repeatedly featured in research findings as a core deficit in antisocial youth. Most notably, Cohen and Strayer (1996), using videotaped vignettes of persons in affective events and self-report measures of empathy, found that dispositional empathy, as measured by assessing both affective and cognitive components, was lower among conduct-disordered adolescents than comparison youth and was inversely related to antisocial and aggressive attitudes. The degree to which both the cognitive and the affective components of empathy differ in their relation to aggressive and persistent antisocial behaviour is an important issue that has been inadequately examined in the research literature (Cohen \& Strayer, 1996). The current study examined the relationship between empathy and persistent antisocial behaviour by examining group-related differences in both the cognitive and affective components of dispositional empathy.

\section{Empathy and Gender}

A consistent finding running through the research on empathy is evidence that young girls and female adolescents score significantly higher than their male counterparts on dispositional empathy. This is true for both cognitive and affective empathy measured using self-report questionnaires (Eisenberg, 2000). It has been suggested that individuals who display low levels of affective empathy may not 'vicariously' experience the negative emotions associated with the infliction of injury or harm to others, thereby rendering these individuals more susceptible to aggressive or antisocial behaviour in their social interactions (Loudin et al., 2003). In the current study, both affective and cognitive components of empathy were tested to examine whether those gender differences were confirmed.

\section{Current Study}

The present study examined dispositional empathy, an important domain of interpersonal functioning which has been empirically and theoretically implicated in the acquisition and maintenance of persistent antisocial behaviour and psychosocial adjustment in early adulthood. One of the main aims of this study was to investigate gender and group differences between groups of high-risk persistently antisocial, low-risk persistently antisocial and non-antisocial young adults in dispositional empathy. In particular, it was hypothesised that participants 
with a history of persistent antisocial behaviour (both high-risk and low-risk groups) were expected to display comparatively less empathy relative to non-antisocial young adults. Regarding the relationship between gender-related differences and empathy, it was further expected that females will display higher levels of both perspective-taking and affective empathy relative to their male counterparts.

\section{Methodology}

\section{Participants}

Recruitment of participants. The participants in the main study were recruited from the Australian Temperament Project (ATP) which is a unique Australian longitudinal study that has followed the development and psychosocial adjustment of a representative sample of Victorian children from infancy to early adulthood. The ATP study commenced in 1983, when a representative sample of rural and urban Victorian children were recruited to take part in the study $(N=2,443)$. Approximately 65 per cent of the original ATP sample were still participating in the project in 2004 at the age of approximately 20 years. Higher attrition rates have been recorded for participants from lower socio-economic backgrounds and participants whose parents were not born in Australia. However, there appear to be no significant differences between the retained and the non-retained sub-samples on any infancy characteristics (Prior et al., 2000; Smart et al., 2005). Since its inception, there have been 14 waves of data collection by means of annual or biannual mail surveys. Questionnaires have assessed adjustment and development in a number of important domains of functioning as reported by parents, maternal and child health nurses, teachers and the ATP participants themselves. Areas of functioning have included temperament style, behavioural and emotional adjustment, social skills, health, academic progress, interpersonal relationships and family demographic information.

In 2005, a sub-sample $(N=138)$ of the ATP cohort was invited to participate in the present study. At the time of recruitment, participants were 22-23 years of age and these included 87 young adult men and 51 young adult women. The details of study participants are shown in the Table 1 below.

Table 1: Number of Study Participants: Gender by Group

\begin{tabular}{|l|l|l|l|l|l|}
\hline \multicolumn{2}{|c|}{} & \multicolumn{2}{l}{ Group } & Total \\
\hline \multicolumn{2}{|l|}{} & Non-antisocial & low-risk & high-risk & \\
\hline Gender & male & 33 & 23 & 31 & 87 \\
\hline & female & 18 & 17 & 16 & 51 \\
\hline Total & 51 & 40 & 47 & 138 \\
\hline
\end{tabular}

A letter of invitation outlining the relevant consent details was sent to participants inviting them to take part in the study by means of a telephone interview. Participants were recruited from previously identified groups in terms of risk status. New data for the current study was collected during the course of 2005 by way of phone interviews, when participants were 2223 years of age. 


\section{Identification of 'At Risk' Groups}

Participants were recruited from groups identified in the ATP cohort as 'high-risk' persistently antisocial, 'low-risk' persistently antisocial and low/non-antisocial youth. Below is a brief description of the criteria for selection into these three groups. Participants for the current study were selected on the basis of a number of indices used to identify individuals at risk of persistent antisocial behaviour. First, a cumulative risk index was used to identify children who were at risk for later involvement in persistent antisocial behaviour according to their developmental histories (for a detailed description see Smart et al., 2005). Specifically, the following individual characteristics were included in the cumulative risk index as measured at 11-12 years of age:

- highly active temperament style (as reported by parents);

- highly negative reactive temperament style (as reported by parents);

- low task persistent temperament style (as reported by teachers);

- low task orientation temperament style (as reported by teachers);

- high aggression (as reported by parents, teachers and/or children);

- high hyperactivity (as reported by parents, teachers and/or children);

- low cooperativeness (as reported by parents, teachers and/or children); and

- low self-control (as reported by parents, teachers and/or children).

A cut-off of three or more risks at 11-12 years was used to identify children who were at risk for subsequent antisocial behaviour. In particular, three groups were formed.

- Low-risk persistently antisocial $(N=42)$. At 11-12 years, this group had been identified as having had fewer than three childhood risks and from 13-18 years had persistently engaged in high levels of adolescent antisocial behaviour (high antisocial behaviour at two or more time points, including the last time point).

- High-risk persistently antisocial $(N=78)$. At 11-12 years, this group had been identified as having had three or more childhood risks and from 13-18 years had persistently engaged in high levels of adolescent antisocial behaviour (high antisocial behaviour at two or more time points, including the last time point).

- Non-antisocial $(N=658)$. This group never engaged in high levels of adolescent antisocial behaviour. Included were a range of individuals (ranging from few to many risks) with an overall average number of childhood risks for this group of 1.6.

(For a more detailed description see Smart et. al., 2005).

\section{Measures}

The following section provides details of the measures used in the current study.

Antisocial behaviour. The classification of participants according to their history of antisocial behaviour relied on existing data previously compiled by the Australian Temperament Project. Antisocial behaviour was assessed at 13-14, 15-16 and 17-18 years using a short form of the Self Report of Delinquency Scale (Moffitt \& Silva, 1988; see Smart et al., 2005 and Vassallo et al., 2002 for further details). Participants reported the number of times they had engaged in each of 12 different antisocial acts (e.g. assault, theft, property damage, 
vandalism) in the 12 months using a four-point scale where $1=$ not at all, $2=$ once, $3=$ twice, and $4=$ more often. Participants were classified as displaying high levels of antisocial behaviour at a particular age if they had engaged in three or more differing antisocial acts during the previous 12 months, and as having displayed little or no antisocial behaviour if they had engaged in fewer than 3 differing antisocial acts during this time frame.

Empathy measure - Interpersonal Reactivity Index. Empathy was assessed using the Interpersonal Reactivity Index (IRI; Davis, 1983) which consists of 28 items divided into four seven-item subscales measuring the dimensions of perspective-taking, fantasy, personal distress and empathic concern. As reported by Davis (1983), alpha reliabilities range from .71 to .77 for these subscales. Adequate internal consistency, test-retest reliability, and concurrent and discriminant validity has been independently demonstrated for this measure (Jolliffe \& Farrington, 2004). For the purposes of this study only two of the four subscales, namely empathic concern (EC) and perspective taking (PT) were used in their entirety. Respondents were required to indicate on a five-point Likert scale how much they identify with specific empathic behaviours. All items are scored on a five-point Likert scale ranging from $1=$ 'does not describe me well' to $5=$ 'describes me very well'. Total empathic concern and perspective taking scores were calculated by averaging the response choices within each of the two subscales.

\section{Main Findings}

\section{Group and Gender Differences for Empathy}

Multivariate Analysis of Variance (MANOVA) tests were used to test for group and gender differences separately for empathy. For empathy, scores were obtained using the mean item scores for each subscale respectively. Two separate MANOVA analyses were conducted using empathy as the dependent variables and group and gender as the independent variables. The multivariate and univariate MANOVA results are summarised in Tables 2 below. Bonferroni adjusted alpha levels were used for all univariate level tests. In addition, a preliminary chi-square test was conducted to test for contingency between gender and group. No significant contingency was found between these two variables $\left(\chi^{2}(2,138)=.79, \mathrm{p}>.05\right)$. 
Table 2: Cohort Differences in Empathy, MANOVA Results: Relationship of Group and Gender to Empathy Dimensions of PT \& EC

\begin{tabular}{|c|c|c|c|c|c|}
\hline & & $F$ & $d f$. & $p$ & partial $\eta^{2}$ \\
\hline Multivariate Effect & & & & & \\
\hline Main & & & & & \\
\hline Gender & & 8.08 & 2,131 & $* * *$ & .110 \\
\hline Group & & 2.70 & 4,264 & * & .039 \\
\hline 2-way interaction & & & & & \\
\hline Gender x Group & & 1.90 & 4,264 & ns & \\
\hline Univariate Effects & & & & & \\
\hline Gender & $\begin{array}{l}\text { PT } \\
\text { EC }\end{array}$ & $\begin{array}{l}1.593 \\
16.29\end{array}$ & $\begin{array}{l}1,132 \\
1,132\end{array}$ & $\begin{array}{l}\text { ns } \\
* * *\end{array}$ & $\begin{array}{l}.012 \\
.110\end{array}$ \\
\hline Group & $\begin{array}{l}\mathrm{PT} \\
\mathrm{EC}\end{array}$ & $\begin{array}{l}2.180 \\
4.42\end{array}$ & $\begin{array}{l}2,132 \\
2,132\end{array}$ & $\begin{array}{l}\text { ns } \\
*\end{array}$ & .032 \\
\hline Gender x Group & $\begin{array}{l}\text { PT } \\
\text { EC }\end{array}$ & $\begin{array}{l}3.062 \\
1.616\end{array}$ & $\begin{array}{l}2,132 \\
2,132\end{array}$ & $\begin{array}{l}\text { ns } \\
\text { ns }\end{array}$ & $\begin{array}{l}.044 \\
.024\end{array}$ \\
\hline $\begin{array}{l}\text { Note: } \mathrm{PT}=\text { perspecti } \\
* * * p<0.001\end{array}$ & tak & $\mathrm{EC}=$ & co & & $<0.01$ \\
\hline
\end{tabular}

For the two empathy subscales, significant main effects for group and gender were found. At the multivariate level, a significant gender effect was noted, suggesting that males and females significantly differed in empathy. Univariate $F$-tests revealed a main effect of gender for empathic concern (EC) only, using a Bonferroni adjusted alpha level of 0.025. Closer examination of the mean scores indicated that females reported higher levels of empathic concern than males $(M=4.06, S D=0.56 ; M=3.60, S D=0.66)$. No gender differences were found for perspective taking (PT).

Additionally, a significant multivariate group effect was found, indicating that the three status groups (high-risk persistently antisocial, low-risk persistently antisocial and non-antisocial) significantly differed in their empathy as measured by the PT and EC subscales of the IRI. Again, at the univariate level, significant group differences (using a Bonferroni adjusted alpha level of 0.025 ) were only observed for the empathic concern (EC) subscale. Post hoc analyses (Tukey's least significant difference [LSD]) indicated that the high-risk persistently antisocial group reported significantly less empathic concern (EC) compared to the non antisocial group $(p<0.05)$.

\section{Conclusions and Implications for Treatment Intervention}

The current study investigated gender and group-related differences in dispositional empathy as measured by the subscales of perspective taking (PT) and empathic concern (EC) on the Interpersonal Reactivity Index (IRI). 
Significant group and gender-related differences were found. Specifically, as predicted, in terms of group-related differences, participants identified as high-risk persistent antisocial youth endorsed lower levels of affective empathy, as measured by the empathic concern subscale on the Interpersonal Reactivity Index (IRI), compared to their non-antisocial counterparts. It is important to note that low-risk persistently antisocial young adults did not display comparable empathy deficits, as evidenced by the lack of differences found in affective empathy, when compared to non-antisocial participants.

As anticipated, these findings suggest that high-risk persistently antisocial youth, whose antisocial behaviour has been evident and arguably entrenched from early childhood, are more likely to be deficient in affective empathy compared to non-antisocial youth who have no previous history of antisocial behaviour. Accordingly, there is evidence to suggest in the current study that the level of risk of persistent antisocial behaviour was significantly related to participants' dispositional affective empathy as reported in young adulthood. Interestingly, contrary to what was anticipated, no group-related differences were noted for the cognitive component of dispositional empathy as measured by perspective taking on the IRI.

Further, in considering gender differences, as anticipated, the results in the current study confirmed the hypothesis that females overall would report higher levels of affective empathy (as measured by empathic concern on the IRI) than males. However, there were no gender differences on the cognitive component of the IRI, as measured by the perspective taking subscale. This is nonetheless consistent with previous research findings pertaining to genderrelated differences and dispositional empathy, which have shown higher levels of dispositional empathy for females, as measured by affective empathy using self-report measures (Cohen \& Strayer, 1996). Moreover, previous research has shown that females tend to report more dispositional empathy than males on self-report measures (Eisenberg, 2000; Eisenberg \& Fabes, 1998). Consistent with earlier findings, the current results suggest a relatively higher level of interpersonal sensitivity in females as evidenced by their higher levels of empathic concern, compared to their male counterparts in young adulthood.

\section{Implications for Treatment Planning and Intervention}

In terms of implications for treatment intervention or planning, it seems plausible given that empathy describes a relatively stable disposition and seems to develop as a result of positive socialisation experiences, the earlier a child is exposed to opportunities to learn empathyrelated responding, the less likely it is that empathy deficits may develop and be maintained. Indeed, given the affective component of empathy is characterised by one's ability to 'vicariously' experience another's feelings, it seems reasonable to suggest that high-risk persistently antisocial youth or males, who were found to characteristically display low levels of affective empathy or empathic concern, may not vicariously experience the negative emotions associated with inducing harm to others (Cohen \& Strayer, 1996; Loudin et al., 2003). Accordingly, individuals low in empathic concern may be more readily inclined to resort to aggressive or antisocial behaviour in their social interactions.

This finding is also consistent with previous research demonstrating that persons with histories of antisocial or aggressive behaviour who demonstrate low levels of affective empathy may be particularly unresponsive to social cues required in identifying others' emotions, possibly due to self-focused arousal and/or inadequate or coercive emotional response patterns encountered in their reciprocal social interactions in early socialisation (Cohen \& Strayer, 
1996; Patterson, Capaldi \& Bank, 1991). Furthermore, given the evident gender disparity noted for affective empathy in the current study favouring females, it would be important to independently consider the potential deficits in affective empathy that may be gender specific, prior to commencing any treatment planning or intervention to enhance the empathy skills for young adults. Again, one possible explanation for this gender discrepancy in affective empathy are stronger socialisation pressures arguably incumbent on female youth to express feelings of concern towards others in their social interactions compared to the relative lack of such expectations in male youth, which may be reflected in differential socialisation experiences (Loudin et al., 2003).

Nonetheless, while the results suggest that there is a need to target the affective component of dispositional empathy in any future initiatives aimed at the preventative treatment of persistent antisocial behaviour, an important consideration is that young adults are not necessarily a homogeneous group, as defined by gender or group status, and potential empathy deficits should arguably be individually assessed in order to enable the formulation and implementation of effective and adequately responsive treatment programs.

In conclusion, the current findings indicate that empathy represents a promising target for interventions designed to prevent or reduce persistent antisocial behaviour. Yet undoubtedly in order for clinical practice and public policy to have any significant impact in the prevention and amelioration of persistent antisocial behaviour, there is a need for sustained momentum and continuity in our efforts to better understand and adequately address the problem of persistent antisocial behaviour.

\section{Acknowledgement}

I would like to acknowledge the invaluable assistance of my supervisors, Dr Mary Ainley, Associate Professor, University of Melbourne, and Ms Diana Smart, Project Manager, Australian Temperament Project, Australian Institute of Family Studies, Melbourne, Australia. This paper is based on the author's doctoral research findings conducted at the University of Melbourne in affiliation with the Australian Institute of Family Studies.

\section{References}

Australian Institute of Criminology (2006) Australian Crime: Facts and Figures 2005. Canberra. Australian Institute of Criminology.

Bor, W., McGee, T. R., Hayatbakhsh, R. \& Najman, J. (2007). The young adult outcomes of childhood and adolescent antisocial behavior: An Australian cohort study. University of Queensland, Criminology Research Council.

Brennan, P. A., Hall, J., Bor, W., Najman, J. M., \& Williams, G. (2003). Integrating biological and social processes in relation to early-onset persistent aggression in boys and girls. Developmental Psychology, 39(2), 309-323.

Carlo, G., Raffaelli, N., Laible, D. J., \& Meyer, K. A. (1999). Why are girls less physically aggressive than boys? Personality and parenting mediators of physical aggression. Sex Roles, 40, 711729.

Caspi, A. (2000). The child is father of the man: Personality continuities from childhood to adulthood. Journal of Personality and Social Psychology, 78(1), 158-172.

Cesaroni, C., \& Peterson-Badali, M. (2005). Young offenders in custody: risk and adjustment. Criminal Justice and Behavior, 32(3), 251-277. 
Cohen, D., \& Strayer, J. (1996). Empathy in conduct-disordered and comparison youth. Developmental Psychology, 32, 988-998.

Connor, D. F. (2002). Aggression and antisocial behavior in children and adolescence: Research and treatment. New York: Guilford Press.

Davis, M. H. (1983). Measuring individual differences in empathy: Evidence for a multidimensional approach. Journal of Personality and Social Psychology, 44(1), 113-126.

Eisenberg, N. (2000). Emotion, regulation, and moral development. Annual Review of Psychology, 51, 665-697.

Eisenberg, N., \& Fabes, R. A. (1998). Prosocial development. In W. Damon (Series Ed.) \& N. Eisenberg (Vol. Ed.), Handbook of child psychology (5 ${ }^{\text {th }}$ ed.): Vol. 3. Social, emotional and personality development (pp. 701-778).

Eisenberg. N., \& Miller, P. A. (1987). The relation of empathy to prosocial and related behaviors. Psychological Bulletin, 101(1), 91-119.

Farrington, D. P. (1995). The development of offending and antisocial behavior from childhood: Key findings from the Cambridge Study in Delinquent Development. Journal of Child Psychology and Psychiatry, 36, 929-964.

Hoffman, M. L. (2000). Empathy and moral development: Implications for caring and justice. Cambridge, UK: Cambridge University Press.

Jolliffe, D., \& Farrington, D. P. (2004). Empathy and offending: A systematic review and meta-analysis. Aggression and Violent Behavior, 9(5), 441-476.

Loeber, R. \& Coie, J. (2001). Continuities and discontinuities of development with particular emphasis on emotional and cognitive components of disruptive behavior. In J. Hill \& B. Maughan (Eds.), Conduct disorders in childhood and adolescence (pp. 379-407). Cambridge, UK: Cambridge University Press.

Loeber, R., Green, S. M., \& Lahey, B. B. (2003). Risk factors for adult antisocial personality. In D. P. Farrington \& J. W. Coid (Eds.), Early prevention of adult antisocial behavior (chapter 3). United Kingdom: Cambridge University Press.

Loudin, J. L., Loukas, A., \& Robinson, S. (2003). Relational aggression in college students: Examining the roles of social anxiety and empathy. Aggressive Behavior, 29, 430-439.

Maughan, B. A., \& Rutter, M. (2001). Antisocial children grown up. In J. Hill \& B. Maughan (Eds.), Conduct disorders in childhood and adolescence (pp. 507-552). Cambridge, UK: Cambridge University Press.

Moffit, T. E. (1993). Adolescence-limited and life-course persistent antisocial behavior: A developmental taxonomy. Psychological Review, 100, 674-701.

Moffit, T. E., Caspi, A., Harrington, H. \& Milne, B. J. (2002). Males on the life-course persistent and adolescent-limited antisocial pathways: Follow-up at age 26 years. Development and Psychopathology, 14, 179-207.

Moffitt, T. E., \& Silva, P. A. (1988). Self-reported delinquency: Results from an instrument for New Zealand. Australian and New Zealand Journal of Criminology, 21, 227-240.

Patterson, G. R., Capaldi, D. N., \& Bank, L. (1991). An early starter model for predicting delinquency. In D. J. Pepler \& K. H. Rubin (Eds.), The development and treatment of childhood aggression (pp. 139-168). Hillsdale, NJ: Erlbaum.

Pettit, G. S. \& Dodge, K. A. (2003). Violent children: Bridging development, intervention and public policy. Developmental Psychology, 39(2), 187-188.

Smart, D., Richardson, N., Sanson, A., Dussuyer, I., Marshall, B., Toumbourou, J. W., Prior, M. \& Oberklaid, F. (2005), Patterns and precursors of adolescent antisocial behaviour. Outcomes and Connections: The Third Report. Australian Institute of Family Studies and Crime Prevention Victoria, Melbourne.

Vassallo, S., Smart, D., Sanson, A., Dussuyer, I., McHenry, B., Toumbourou, J. W., Prior, M., \& Oberklaid, F. (2002). Patterns and precursors of adolescent antisocial behavior: First report. Crime Prevention Victoria, Melbourne. 
Zoccolillo, M., Pickles, A., Quinton, D., Rutter, M. (1992). The outcome of childhood conduct disorder: Implications for defining adult personality disorder and conduct disorder. Psychological Medicine, 22, 971-986.

\section{About the Author}

Dr. Effie Zafirakis

Dr. Zafirakis is currently lecturing at RMIT University in Melbourne, Australia, in the Criminal Justice and Juris Doctor programs in law. Dr. Zafirakis qualified as a lawyer and as a forensic psychologist and has a keen interest in the interface between psychology and law. Dr. Zafirakis holds degrees in Science majoring in Psychology (BSc) and in Law (LLB) from Monash University, and a Doctorate in Psychology (DPsych Forensic) from the University of Melbourne. Dr. Zafirakis has also practiced as a criminal lawyer with Victoria Legal Aid. 